This item was submitted to Loughborough's Research Repository by the author.

Items in Figshare are protected by copyright, with all rights reserved, unless otherwise indicated.

\title{
Failure analysis of plain woven glass/epoxy laminates: Comparison of off- axis and biaxial tension loadings
}

\section{PLEASE CITE THE PUBLISHED VERSION}

http://dx.doi.org/10.1016/j.polymertesting.2017.04.010

\section{PUBLISHER}

(c) Elsevier

\section{VERSION}

AM (Accepted Manuscript)

\section{PUBLISHER STATEMENT}

This work is made available according to the conditions of the Creative Commons Attribution-NonCommercialNoDerivatives 4.0 International (CC BY-NC-ND 4.0) licence. Full details of this licence are available at: https://creativecommons.org/licenses/by-nc-nd/4.0/

\section{LICENCE}

CC BY-NC-ND 4.0

\section{REPOSITORY RECORD}

Cai, Deng'an, Ju Tang, Guangming Zhou, Xiaopei Wang, Chao Li, and Vadim V. Silberschmidt. 2019. "Failure Analysis of Plain Woven Glass/epoxy Laminates: Comparison of Off-axis and Biaxial Tension Loadings". figshare. https://hdl.handle.net/2134/25061. 


\title{
Failure analysis of plain woven glass/epoxy laminates: Comparison of off-axis and biaxial tension loadings
}

\author{
Deng'an Cai a , Ju Tang ${ }^{\mathrm{b}}$, Guangming Zhou ${ }^{\text {a, * }}$, Xiaopei Wang ${ }^{\text {a }}$, Chao Li ${ }^{\text {a, c }}$, \\ Vadim V. Silberschmidt ${ }^{\mathrm{d}}$ \\ a State Key Laboratory of Mechanics and Control of Mechanical Structures, Nanjing University of Aeronautics and Astronautics, Nanjing 210016, PR China ${ }^{\text {b }}$ The Sixtieth Institute \\ of the Headquarters of General Staff, Nanjing 210016, PR China \\ ${ }^{c}$ Nanjing Fiberglass $R$ \& D Institute, Nanjing 210012, PR China \\ ${ }^{\mathrm{d}}$ Wolfson School of Mechanical, Electrical and Manufacturing Engineering, Loughborough University, Leicestershire, LE11 3TU, UK
}

\begin{abstract}
An experimental study was focused on investigation of the failure properties of plain woven glass/epoxy composites under offaxis and biaxial tension loading conditions. Four fibre orientations $\left(0^{\circ}, 15^{\circ}, 30^{\circ}\right.$ and $45^{\circ}$ with respect to the load direction) were considered for off-axis tests and two biaxial load ratios for biaxial tests to study failure characteristics and mechanism. Four classical polynomial failure criteria -Tsai-Hill, Hoffman, Tsai-Wu and Yeh-Stratton - were analysed comparatively to predict offaxis and biaxial failure strength of the composites. For failure prediction of the plain woven composites under multiaxial tension loads, the Tsai-Wu criterion was modified by introducing an interaction coefficient $F_{12}$ obtained from $45^{\circ}$ off-axis or biaxial tension tests and the Yeh-Stratton criterion was modified with the interaction coefficient $B_{12}=0$ or obtained from the biaxial tension test. The former criterion was found to have higher accuracy. Finally, according to macroscopic and microscopic studies, the failed specimens showed mostly distinct failure with a specific fracture orientation, mainly exhibiting fibre or fabric tensile fracture mode and a combination of matrix cracking and delamination, both in off-axis and cruciform samples.
\end{abstract}

Keywords:

Plain woven composite

Off-axis and biaxial tests

Tensile strength

Failure criteria

Fracture modes

\section{Introduction}

Thanks to their lightweight and high mechanical performance, fibre-reinforced composite laminates are increasingly used for structural components in aerospace, automotive, energy and marine industries. Numerous cases dealing with the design of composite structures show that there is a need for more refined analysis taking into account multiaxial failure behaviour of composite laminates [1-7].

A large number of works on damage and failure models has been completed and validated based on results of uniaxial tests. However, World Wide Failure Exercises (WWFE-I, II and III) [1-3,8-10], global comparisons of predictions of the most prominent failure model against common experimental data, revealed validation challenges due to scarcity of comparisons between theoretical results and test data obtained in multiaxial loading

\footnotetext{
* Corresponding author.

E-mail address: zhougm@nuaa.edu.cn (G. Zhou).
}

regimes. Therefore, paucity of reliable experimental data for biaxial or multiaxial loading cases is still a significant matter. Generally, several multiaxial test methods for composites and respective specimen configurations were reviewed in the literature [4,11-13]. It is important to state $[14,15]$ that multiaxial stress states in fibrereinforced composites can be generated mainly with off-axis specimens under tension/compression loading, cruciform specimens under biaxial loading and tube specimens under tension/ compression-torsion loading. Because of spatially varying fibre orientation in a lamina, a local multiaxial stress state can be achieved with off-axis loading conditions. Thus, even if a loading regime is uniaxial, the local stress state is multiaxial. This kind of multiaxiality, originating from the anisotropic behaviour of the lamina, was termed internal multiaxiality [14]. Contrarily, an external multiaxiality condition takes places when external loads are applied along different directions, such as in cruciform or tube specimens.

In recent years, a number of studies have investigated multiaxial behaviour and failure properties (including internal and external 
multiaxiality) of unidirectional (UD) or multidirectional (MD) laminates with different stacking sequences [1-4,16-20]. There is still a limited number of works analysing multiaxial strength of fabric-reinforced composites such as plain woven composite laminates. Currently, such laminates are widely used in plane or shell aerospace and automotive structures that are often subjected to off-axis and biaxial loadings. Therefore, it is essential to assess failure behaviour of these materials in such loading cases. Recently, Bere et al. [21] proposed a mathematical fracture model for bidirectional reinforced composite material under uniaxial and biaxial loads. Zhou et al. [22] developed an anisotropic progressive damage model (PDM) accounting for shear nonlinearity to evaluate strength of a 2D plain weave composite under various uniaxial and biaxial loading conditions using a representative volume cell (RVC). Moreover, Zhang et al. [23] presented their off-axis and biaxial failure analyses for glass woven fabrics, with material strength and failure modes depending on stress ratio and off-axis angle of specimens, as well as their loading rate.

Generally, the macroscopic failure criteria, also called phenomenological failure criteria, employ a polynomial equation based on uniaxial strength parameters to evaluate failure properties under any stress state, not considering specific failure modes or mechanism. Their relative simplicity make them attractive for applications. However, disagreements between predictions of the existing criteria and test results occur often for complex stress states. Therefore, more verification experiments involving combined stress states as well as amendments or improvements of the failure criteria are always popular. An off-axis loading test is the easiest way to generate a complex stress state, which can be used to study and verify the failure criteria of composite materials. The only limitation of off-axis specimens is a specific multiaxial stress ratio at a given off-axis angle. Comparatively, cruciform specimens used in biaxial tests can produce various biaxial or multiaxial stress ratios according to the employed test facility. Many researchers studied biaxial failure properties of composite materials experimentally and numerically to obtain more experimental biaxial test data and understand deeper behaviour of cruciform specimens [18,24-30]. Despite plenty of research efforts recently devoted to investigation of failure behaviour of composite laminates under multiaxial loading conditions, their damage mechanism and respective failure theories are still not fully established.

In this work, the failure analysis and strength prediction for the plain woven glass fabric-reinforced epoxy composites were investigated under off-axis and biaxial tension loading conditions employing several quadratic criteria. These criteria have been fully investigated and validated by many experimental correlations for unidirectional fibre-reinforced composites but only few for plain woven composites. Uniaxial and biaxial tension tests were performed to study behaviour and failure mechanism of the composite laminates using off-axis and cruciform specimens. The current failure criteria were compared to predict off-axis and biaxial failure strength of the composites; the effects of off-axis and biaxial loads on the predicted results were analysed. The macroscopic and microscopic failure modes and mechanism are also discussed.

\section{Materials, specimen preparation and test equipment}

The material under investigation was a 2D plain woven E-glass/ epoxy composite with a fabric areal density of $210 \mathrm{~g} / \mathrm{m}^{2}$ (Fig. 1). The matrix material was epoxy-resin WSR618 system, with benzene dimethylamine used as a resin-curing agent and butyl phthalate as viscous additive. For off-axis specimens, ten similar layers were stacked together in order to obtain a laminate with a desired lay-up sequence of $[0]_{10}$, where 0 represents a plain woven fabric ply with yarns oriented in $0^{\circ}$ and $90^{\circ}$. For cruciform specimens, the stacked sequence of laminate was $[0]_{21}$. The layer-by-layer stacking was performed manually. Subsequently, the vacuum bagging technique was used at ambient temperature, as shown in Fig. 2. The plate was fabricated for $4 \mathrm{~h}$ negative-pressure-assisted curing, which is known to reduce typical defects in the laminate such as voids in matrix, delamination between layers or cracks between fibre and matrix. Finally, an aging treatment at $60{ }^{\circ} \mathrm{C}$ for $4 \mathrm{~h}$ was followed after $24 \mathrm{~h}$ of a room-temperature curing process.

The composite laminates studied in this work were orthotropic with the same in-plane properties for the longitudinal (or warp) and transverse (or weft) directions. Their properties obtained from a series of basic mechanical tests (i.e. axial tensile, compressive and $+45 /-45$ tensile tests) are listed in Table 1.

Off-axis and cruciform specimens, shown in Figs. 3 and 4, respectively, were cut from the produced laminated plates using a water-cooled diamond wheel cutter and polished with standard techniques. To reduce the gripping effects, aluminium tabs were used for off-axis specimens (Fig. 3) to protect the specimen surface and increase friction between the specimen and the grips, which were not required for cruciform specimens thanks to thinning in the central zone (Fig. 4).

Uniaxial tension tests were performed using an MTS testing system, equipped with hydraulic grips; a computer with a control system was connected to it for data acquisition. Biaxial tension tests were carried out on a SDS100 electro-hydraulic servo biaxial testing machine, with a capacity of $\pm 100 \mathrm{kN}$ for each of its two orthogonal directions with four independent servo-hydraulic cylinders [31].

\section{Experiment}

The experimental study was conducted in two stages: manufacturing of composite flat specimens and testing of off-axis and cruciform specimens. The actual dimensions of manufactured specimens were measured and recorded before testing. Four onaxis and off-axis angles (i.e. $\theta=0^{\circ}, 15^{\circ}, 30^{\circ}$ and $45^{\circ}$, see Fig. 3 ) were chosen for the tested specimens, thanks to the same properties for the warp and weft directions. The uniaxial tensile tests (Fig. 5a) were performed using the MTS test machine under displacement control, following ISO 527-4. The biaxial tensile tests with two biaxial load ratios (i.e. $f=F_{x} / F_{y}=1 / 1$ and $2 / 1$ ) were completed with the SDS100 electro-hydraulic servo biaxial testing machine (Fig. 5b) under force control (to ensure the constant biaxial load ratio).

\section{Failure criteria}

A brief summary of several most frequently used quadratic polynomial failure criteria is presented here - Tsai-Hill, Hoffman, Tsai-Wu and Yeh-Stratton. These criteria employ a polynomial equation based on uniaxial strength parameters in principal material directions to evaluate the failure properties under any stress state for plane-stress conditions. The uniaxial tensile (index $t$ ) and compressive (index $c$ ) strength in the longitudinal $(X)$ and transverse $(Y)$ directions, $X_{t}, X_{c}, Y_{t}$, and $Y_{c}$, respectively, and the shear strength $S_{12}$ are needed.

The Tsai-Hill criterion [32] is a stress-based and failure-modeindependent criterion, considering stress interaction based on a modified version of the yield criterion for metals. According to this criterion, the failure is predicted for the plane-stress state as

$\frac{\sigma_{1}^{2}}{X^{2}}-\frac{\sigma_{1} \sigma_{2}}{X^{2}}+\frac{\sigma_{2}^{2}}{Y^{2}}+\frac{\tau_{12}^{2}}{S_{12}^{2}}=1$,

where $X$ and $Y$ are either tensile or compression strength depending 


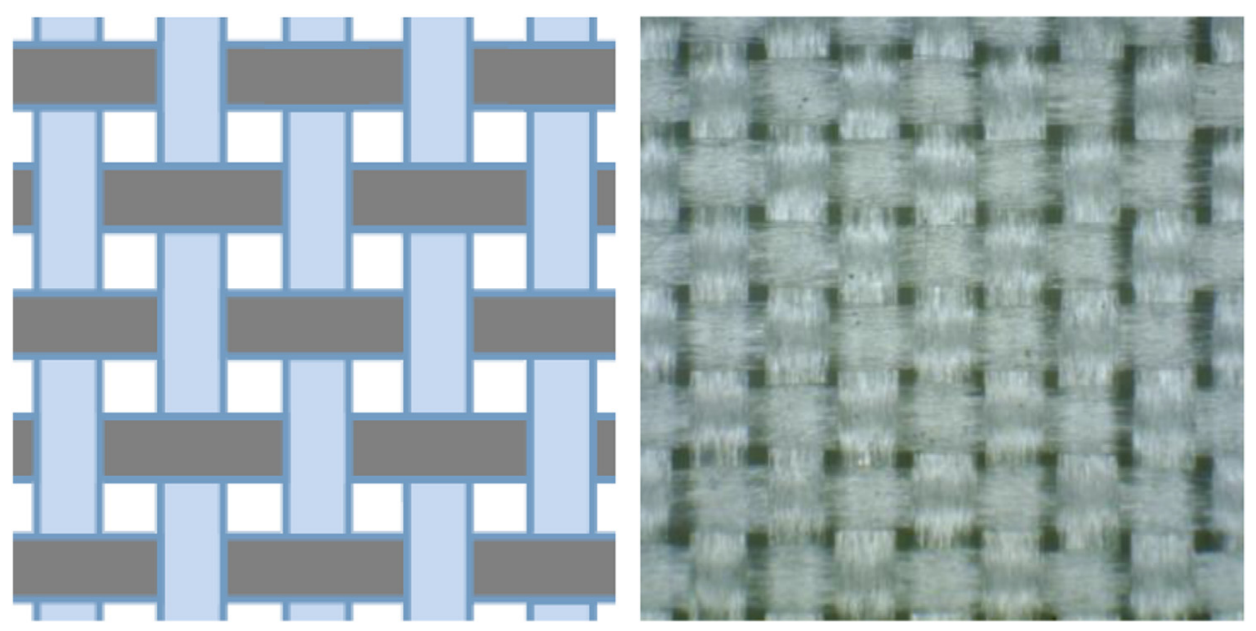

Fig. 1. Plain woven glass fabric.

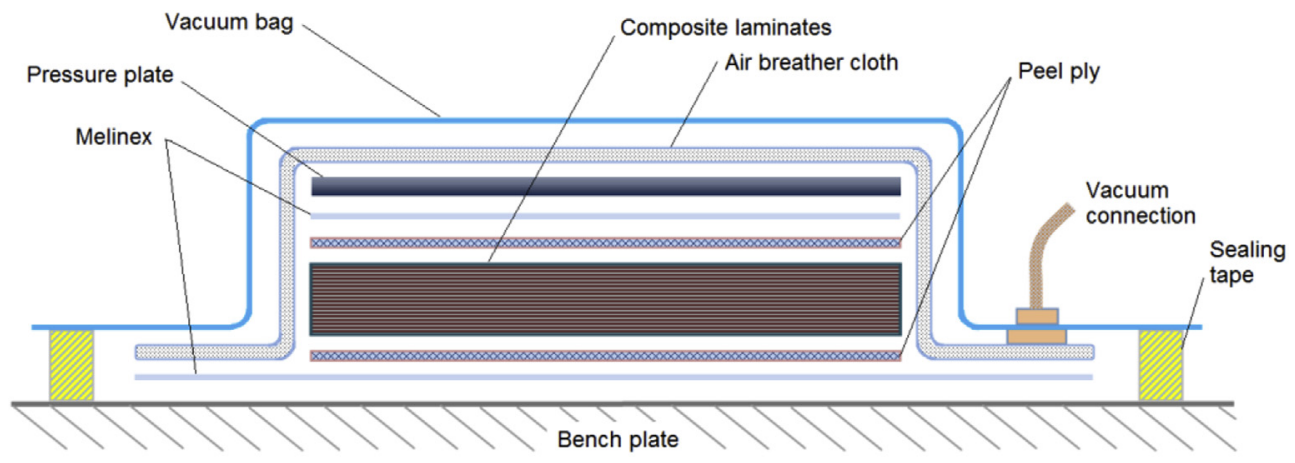

(a)

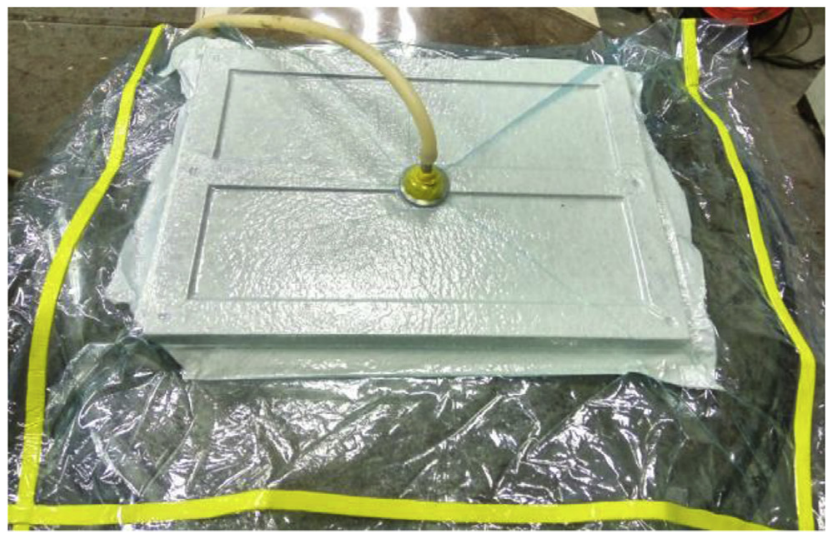

(b)

Fig. 2. Vacuum bagging technique: (a) schematic diagram; (b) actual installation.

on the sign of the respective stresses.

The Hoffman criterion [33] contains linear terms of stresses and also considers different material behaviour in tension and compression. Under the plane-stress condition, the Hoffman failure criterion has the following form: 
Table 1

Mechanical properties of plain woven glass/epoxy composite lamina.

\begin{tabular}{lllll}
\hline$E_{11}[\mathrm{GPa}]$ & $E_{22}[\mathrm{GPa}]$ & $G_{12}[\mathrm{GPa}]$ & $v_{12}$ & \\
21.50 & 21.50 & 3.42 & 0.11 & \\
\hline$X_{t}[\mathrm{MPa}]$ & $X_{c}[\mathrm{MPa}]$ & $Y_{t}[\mathrm{MPa}]$ & $Y_{c}[\mathrm{MPa}]$ & $S_{12}[\mathrm{MPa}]$ \\
452.37 & 312.69 & 452.37 & 312.69 & 69.76 \\
\hline
\end{tabular}

$\left(\frac{1}{X_{t}}-\frac{1}{X_{c}}\right) \sigma_{1}+\left(\frac{1}{Y_{t}}-\frac{1}{Y_{c}}\right) \sigma_{2}+\frac{\sigma_{1}^{2}}{X_{t} X_{c}}+\frac{\sigma_{2}^{2}}{Y_{t} Y_{C}}+\frac{\tau_{12}^{2}}{S_{12}^{2}}-\frac{\sigma_{1} \sigma_{2}}{X_{t} X_{c}}=1$

The Tsai-Wu failure criterion [34] for anisotropic materials formulated for the case of an orthotropic lamina in a general state of plane stress can be expressed as

$$
\left(\frac{1}{X_{t}}-\frac{1}{X_{c}}\right) \sigma_{1}+\left(\frac{1}{Y_{t}}-\frac{1}{Y_{c}}\right) \sigma_{2}+\frac{\sigma_{1}^{2}}{X_{t} X_{c}}+\frac{\sigma_{2}^{2}}{Y_{t} Y_{c}}+\frac{\tau_{12}^{2}}{S_{12}^{2}}+2 F_{12} \sigma_{1} \sigma_{2}
$$$$
=1 \text {, }
$$

where $F_{12}$ is the interaction coefficient of the product of $\sigma_{1}$ and $\sigma_{2}$, which has to be evaluated from a test with non-zero $\sigma_{1}$ and $\sigma_{2}$. With the coefficient $F_{12}=-\frac{1}{2 X_{t} X_{c}}$, the criterion can be transformed to the Hoffman formulation. The magnitude of $F_{12}$ is, however, constrained by the following inequality for the stability criterion:

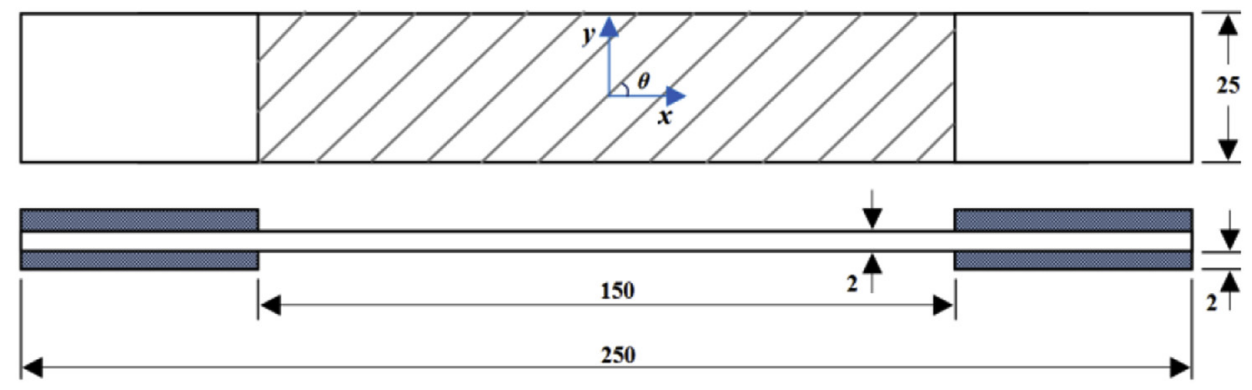

Fig. 3. Dimensions of off-axis specimen.
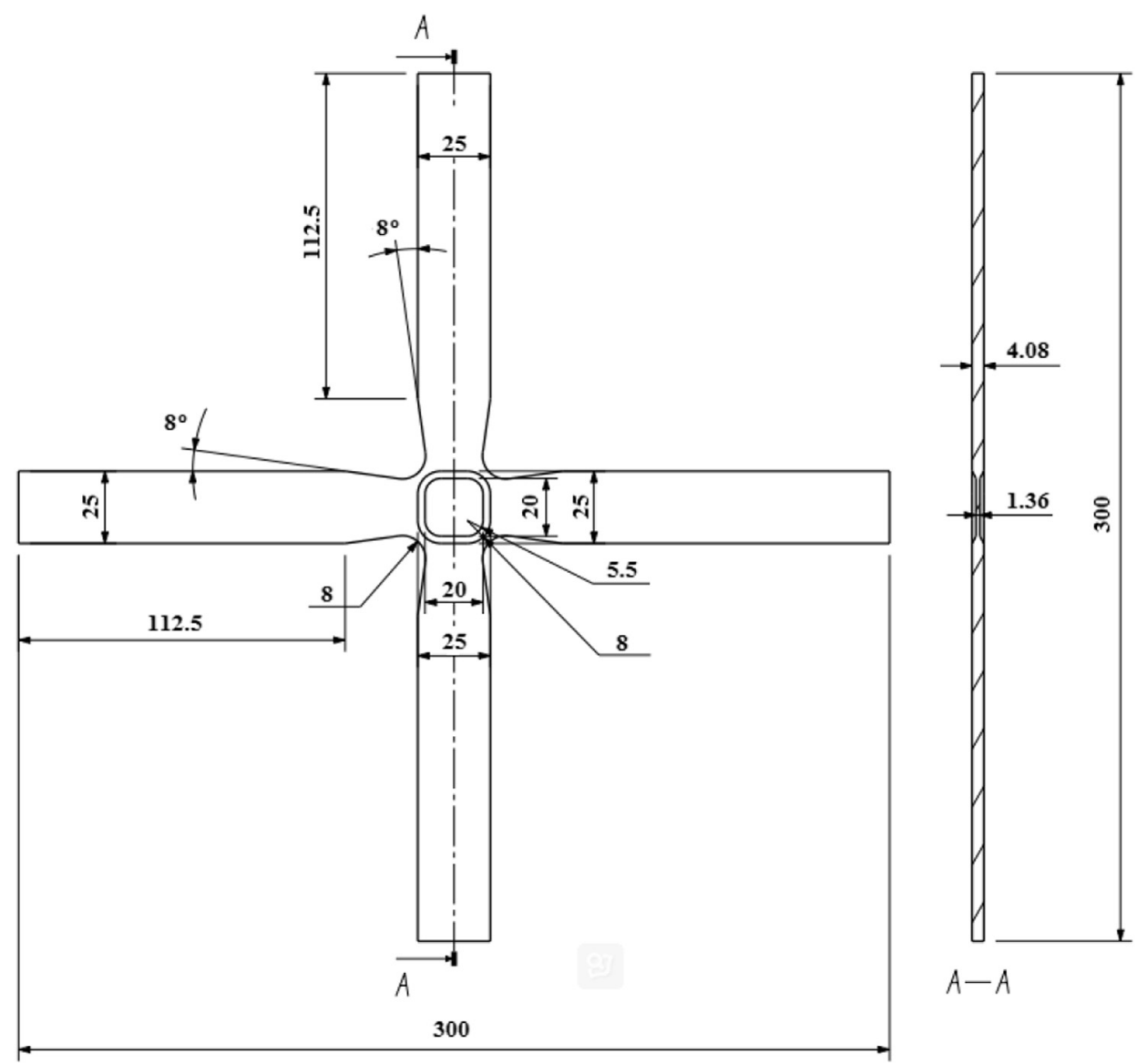

$A-A$

Fig. 4. Geometry and dimensions of cruciform specimen. 


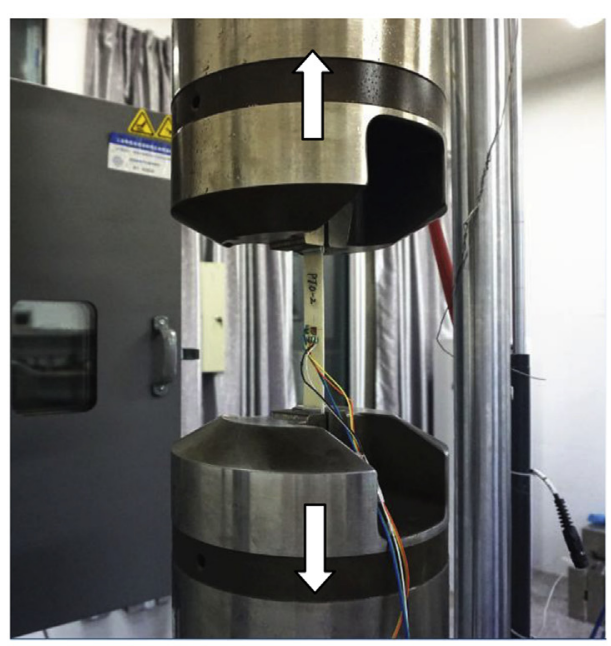

(a)

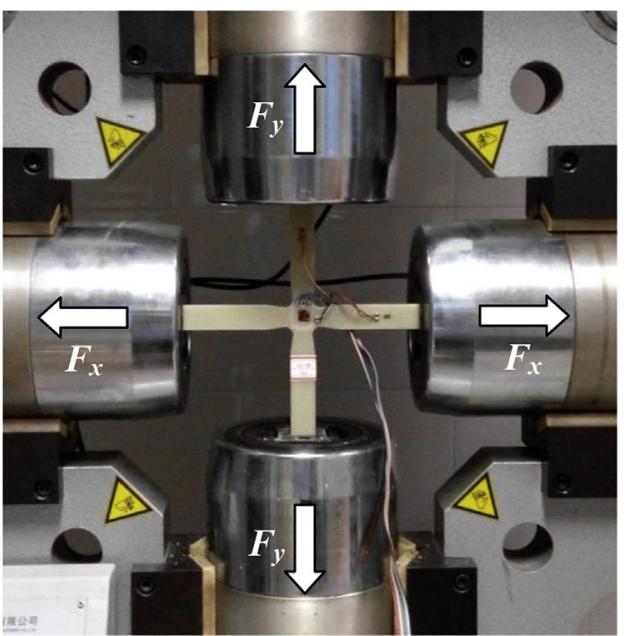

(b)

Fig. 5. Uniaxial (a) and biaxial (b) tension loading.

$-\frac{1}{\sqrt{X_{t} X_{c} Y_{t} Y_{c}}}<F_{12}<\frac{1}{\sqrt{X_{t} X_{c} Y_{t} Y_{c}}}$

The Yeh-Stratton criterion [35] is based on the first order of normal stresses, the second order of shear stresses and the interaction term. The generalized form for composite materials can be written as

$\frac{\sigma_{1}}{X}+\frac{\sigma_{2}}{Y}+\frac{\tau_{12}^{2}}{S_{12}^{2}}+B_{12} \sigma_{1} \sigma_{2}=1$

where $B_{12}$ is the coefficient of the interaction term of normal stresses to be determined from experiments.

For the off-axis specimen, the stresses in a ply with fibres oriented at angle $\theta$ to the direction of the applied stress can be obtained as follows:

$\sigma_{1}=\sigma_{x} \cos ^{2} \theta, \sigma_{2} \sin ^{2} \theta, \tau_{12}=-\sigma_{x} \sin \theta \cos \theta$.

Therefore, for uniaxial tensile stress $\sigma_{x}$ with a given value of offaxis angle $\theta$, the aforementioned criteria, namely, Eqs. (1)-(3) and (5), can be formulated as follows:

Tsai-Hill

$\sigma_{x}^{2}\left[\left(\frac{1}{S_{12}^{2}}-\frac{1}{X^{2}}\right) \cos ^{2} \theta \sin ^{2} \theta+\left(\frac{\cos ^{4} \theta}{X^{2}}+\frac{\sin ^{4} \theta}{Y^{2}}\right)\right]=1$

Hoffman

$$
\begin{aligned}
& \sigma_{x}^{2}\left[\left(\frac{1}{S_{12}^{2}}-\frac{1}{X_{t} X_{c}}\right) \cos ^{2} \theta \sin ^{2} \theta+\left(\frac{\cos ^{4} \theta}{X_{t} X_{c}}+\frac{\sin ^{4} \theta}{Y_{t} Y_{c}}\right)\right]+\sigma_{x}\left[\left(\frac{1}{X_{t}}\right.\right. \\
& \left.\left.-\frac{1}{X_{c}}\right) \cos ^{2} \theta+\left(\frac{1}{Y_{t}}-\frac{1}{Y_{c}}\right) \sin ^{2} \theta\right] \\
& \quad=1
\end{aligned}
$$

$$
\begin{aligned}
\sigma_{x}^{2} & {\left[\left(\frac{1}{S_{12}^{2}}+2 F_{12}\right) \cos ^{2} \theta \sin ^{2} \theta+\left(\frac{\cos ^{4} \theta}{X_{t} X_{c}}+\frac{\sin ^{4} \theta}{Y_{t} Y_{c}}\right)\right]+\sigma_{x}\left[\left(\frac{1}{X_{t}}\right.\right.} \\
& \left.\left.-\frac{1}{X_{c}}\right) \cos ^{2} \theta+\left(\frac{1}{Y_{t}}-\frac{1}{Y_{c}}\right) \sin ^{2} \theta\right] \\
& =1
\end{aligned}
$$

Yeh-Stratton

$$
\left.\sigma_{x}^{2} \frac{1}{S_{12}^{2}}+B_{12}\right) \cos ^{2} \theta \sin ^{2} \theta+\sigma_{x}\left(\frac{\cos ^{2} \theta}{X}+\frac{\sin ^{2} \theta}{Y}\right)=1
$$

\section{Comparisons between experimental data and theoretical results}

\subsection{Failure prediction results}

In particular, for the Tsai-Wu and Yeh-Stratton criteria, the coefficients of the interaction term (i.e. $F_{12}$ and $B_{12}$ ) play an important role in predicting the failure properties of composite materials. In order to fully understand the effect of these coefficients on the predictive accuracy of the criteria, four different values for each of coefficients $F_{12}$ and $B_{12}$ (including empirical and experimental ones) are herein analysed for comparison. The calculation methods and values are listed in Tables 2 and 3, with two empirical evaluations (i.e. $F_{12}-1 \#$ and $B_{12}-1 \# ; F_{12}-2 \#$ and $B_{12}-2 \#$ ) and two experimental calculations (i.e. $F_{12}-3 \#$ and $B_{12}-3 \# ; F_{12}-4 \#$ and $B_{12}-4 \#$ ) considered. The magnitudes of $F_{12}-3 \#$ and $B_{12}-3 \#$ in Tables 2 and 3 can be determined using $45^{\circ}$ off-axis tension tests, calculated with Eqs. (11) and (12), since $\sigma_{1}=\sigma_{2}=\sigma / 2$ and $\tau_{12}=-\sigma / 2$ :

$$
\left.F_{12}=\frac{2}{\sigma^{2}}\left[1-\frac{\sigma}{2}\left(\frac{1}{X_{t}}-\frac{1}{X_{c}}+\frac{1}{Y_{t}}-\frac{1}{Y_{c}}\right)-\frac{\sigma^{2}}{4} \frac{1}{X_{t} X_{c}}+\frac{1}{Y_{t} Y_{c}}+\frac{1}{S_{12}^{2}}\right)\right]
$$


Table 2

Coefficients of interaction term of normal stresses in Tsai-Wu criterion.

\begin{tabular}{|c|c|c|c|c|c|}
\hline No. & & $F_{12}-1 \#$ & $F_{12}-2 \#$ & $F_{12}-3 \#$ & $F_{12}-4 \#$ \\
\hline \multirow[t]{2}{*}{$F_{12}$} & Method & 0 & $-\frac{1}{2 \sqrt{X_{X} X_{X} Y_{Y} Y_{Y}}}$ & $45^{\circ}$ off-axis tension & Biaxial tension with $f=1 / 1$ \\
\hline & $\begin{array}{l}\text { Value } \\
{\left[\times 10^{-6} \mathrm{MPa}^{-2}\right]}\end{array}$ & 0 & -3.535 & 7.086 & 6.160 \\
\hline
\end{tabular}

Table 3

Coefficients of interaction term of normal stresses in Yeh-Stratton criterion.

\begin{tabular}{|c|c|c|c|c|c|}
\hline No. & & $B_{12}-1 \#$ & $B_{12}-2 \#$ & $B_{12}-3 \#$ & $B_{12}-4 \#$ \\
\hline \multirow[t]{2}{*}{$B_{12}$} & Method & 0 & $-\frac{1}{X Y}$ & $45^{\circ}$ off-axis tension & Biaxial tension with $f=1 / 1$ \\
\hline & $\begin{array}{l}\text { Value } \\
{\left[\times 10^{-6} \mathrm{MPa}^{-2}\right]}\end{array}$ & 0 & -4.887 & -63.377 & 0.726 \\
\hline
\end{tabular}

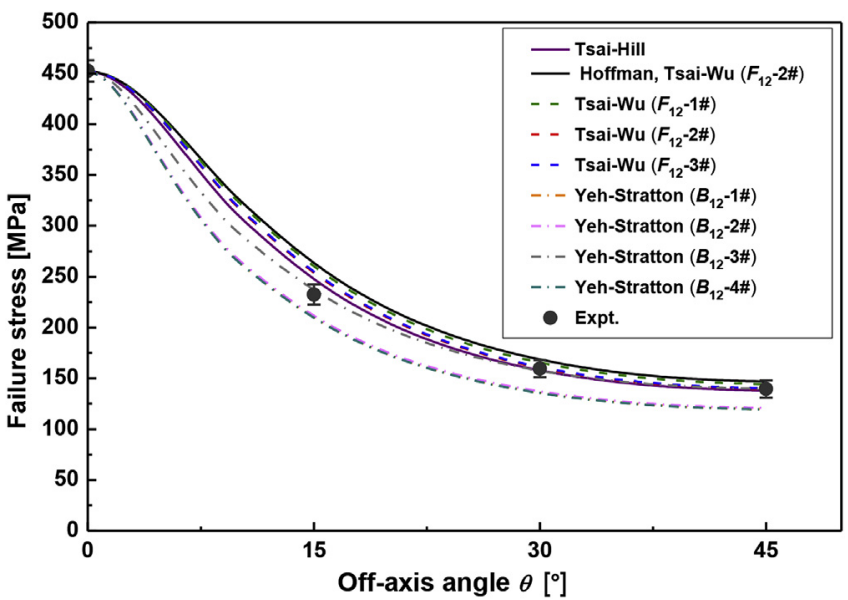

Fig. 6. Predicted and measured off-axis tensile strengths of plain woven glass/epoxy composite laminate.

$B_{12}=\frac{4}{\sigma^{2}}\left[1-\frac{\sigma}{2}\left(\frac{1}{X}+\frac{1}{Y}\right)-\frac{\sigma^{2}}{4 S_{12}^{2}}\right]$,

where $\sigma$ is the off-axis tension stress. In the biaxial tension test with biaxial ratio $f=1 / 1$, the stress state is $\sigma_{1}=\sigma_{2}=\sigma$ and $\tau_{12}=0$ (the shear stress can be ignored due to its very small contribution in the central testing zone of the cruciform specimen). Substituting this state of combined stresses into Eqs. (3) and (5) yields the magnitudes of $F_{12}-4 \#$ and $B_{12}-4 \#$ as follows:
$F_{12}=\frac{2}{2 \sigma^{2}}\left[1-\frac{\sigma}{2}\left(\frac{1}{X_{t}}-\frac{1}{X_{c}}+\frac{1}{Y_{t}}-\frac{1}{Y_{c}}\right)-\sigma^{2}\left(\frac{1}{X_{t} X_{C}}+\frac{1}{Y_{t} Y_{c}}\right)\right]$

$B_{12}=\frac{1}{\sigma^{2}}\left[1-\sigma\left(\frac{1}{X}+\frac{1}{Y}\right)\right]$

In the off-axis tension experiments, $15^{\circ}, 30^{\circ}$ and $45^{\circ}$ off-axis specimens were tested and compared with $0^{\circ}$ specimens. Their load-displacement and stress-strain (nominal stress-nominal strain) behaviour was described in Ref. [36]. The tensile strength of the off-axis specimens was always lower than those of the onaxis ones due to the interaction of tensile and shear stresses. The test results for the off-axis tensile strength are plotted in Fig. 6, in comparison with the critical curves obtained with the four aforementioned criteria. A pronounced effect of the off-axis angle on the measured uniaxial strength of the plain woven glass/epoxy composite is apparent. The increase in the off-axis angle from $0^{\circ}$ to $45^{\circ}$ resulted in a significant decrease in the tensile strength, e.g., the off-axis strength decreased by $48.6 \%, 64.7 \%$ and $69.2 \%$ for the $15^{\circ}$, $30^{\circ}$ and $45^{\circ}$ off-axis specimens, respectively. The decline in the offaxis strength demonstrated a levelling-off trend when the off-axis angle increased from $30^{\circ}$ to $45^{\circ}$. Ten theoretical curves obtained from the four failure criteria with different interaction coefficients captured main trends and showed good agreement with experimental data (Fig. 6). Hence, all these criteria can be applied for predicting the off-axis strength of plain woven glass/epoxy composite laminates, demonstrating some small disparities among them.

The comparison between applications of the failure criteria and the experimental results is summarized in Table 4 (the relative

Table 4

Comparison between predicted results and experimental data of off-axis strength.

\begin{tabular}{|c|c|c|c|c|c|c|c|c|c|}
\hline \multirow[t]{2}{*}{ Criteria } & \multicolumn{3}{|c|}{$15^{\circ}$ off-axis tension } & \multicolumn{3}{|c|}{$30^{\circ}$ off-axis tension } & \multicolumn{3}{|c|}{$45^{\circ}$ off-axis tension } \\
\hline & $\begin{array}{l}\text { Expt. } \\
{[\mathrm{MPa}]}\end{array}$ & $\begin{array}{l}\text { Predicted } \\
{[\mathrm{MPa}]}\end{array}$ & $\begin{array}{l}\text { Error } \\
{[\%]}\end{array}$ & $\begin{array}{l}\text { Expt. } \\
\text { [MPa] }\end{array}$ & $\begin{array}{l}\text { Predicted } \\
{[\mathrm{MPa}]}\end{array}$ & $\begin{array}{l}\text { Error } \\
{[\%]}\end{array}$ & $\begin{array}{l}\text { Expt. } \\
\text { [MPa] }\end{array}$ & $\begin{array}{l}\text { Predicted } \\
{[\mathrm{MPa}]}\end{array}$ & $\begin{array}{l}\text { Error } \\
{[\%]}\end{array}$ \\
\hline Tsai-Hill & 232.52 & 243.88 & 5.01 & 159.59 & 156.81 & -1.74 & 139.52 & 137.89 & -1.17 \\
\hline Hoffman & & 260.03 & 11.96 & & 167.32 & 4.84 & & 146.79 & 5.21 \\
\hline Tsai-Wu $\left(F_{12}-1 \#\right)$ & & 256.65 & 10.51 & & 164.52 & 3.09 & & 144.25 & 3.39 \\
\hline Tsai-Wu $\left(F_{12}-2 \#\right)$ & & 260.03 & 11.96 & & 167.32 & 4.84 & & 146.79 & 5.21 \\
\hline Tsai-Wu $\left(F_{12}-3 \#\right)$ & & 250.25 & 7.75 & & 159.30 & -0.18 & & 139.52 & 0 \\
\hline Tsai-Wu $\left(F_{12}-4 \#\right)$ & & 251.06 & 8.10 & & 159.96 & 0.23 & & 140.11 & 0.42 \\
\hline Yeh-Stratton $\left(B_{12}-1 \#\right)$ & & 205.95 & -11.32 & & 134.95 & -15.44 & & 119.65 & -14.24 \\
\hline Yeh-Stratton $\left(B_{12}-2 \#\right)$ & & 207.70 & -10.57 & & 136.30 & -14.60 & & 120.88 & -13.36 \\
\hline Yeh-Stratton $\left(B_{12}-3 \#\right)$ & & 233.43 & 0.51 & & 156.64 & -1.85 & & 139.52 & 0 \\
\hline Yeh-Stratton $\left(B_{12}-4 \#\right)$ & & 205.69 & -11.43 & & 134.75 & -15.56 & & 119.48 & -14.37 \\
\hline
\end{tabular}


error in Table 4 was calculated with regard to the respective experimental magnitude). Although its expression in this paper is only limited to transversely isotropic material [32], the predictions of the Tsai-Hill criterion were relatively close to the experimental data, with a maximum relative error of $5.0 \%$ (absolute value) for the off-axis angle of $15^{\circ}$ and a minimum relative error of $1.2 \%$ (absolute value) for $45^{\circ}$. The Hoffman criterion gave a slightly overestimated prediction for the off-axis strength with a maximum positive relative error of $12.0 \%$ for $15^{\circ}$, and the predicted curve coincided with that of the Tsai-Hill criterion.

The predicted curves based on the Tsai-Wu criterion with different magnitudes of the interaction coefficient $F_{12}$ lay between those of the Tsai-Hill and Hoffman criteria, where the Tsai-Wu criterion with $F_{12}-2 \#$ was the same as the Hoffman criterion. The Tsai-Wu criterion with $F_{12}-3 \#$ and $F_{12}-4 \#$ provided better results than the Tsai-Hill criterion for off-axis angles of $30^{\circ}$ and $45^{\circ}$. The Yeh-Stratton criterion with different levels of the interaction coefficient $B_{12}$ showed a conservative prediction for the off-axis strength, with the negative relative errors from 10.6\% (absolute value) for $B_{12}-2 \#$ at $15^{\circ}$ to $15.6 \%$ (absolute value) for $B_{12}-4 \#$ at $30^{\circ}$. However, it is interesting that the Yeh-Stratton criterion had the best prediction (even for small off-axis angle, i.e. $15^{\circ}$ ) for $B_{12}-3 \#$, obtained from the $45^{\circ}$ off-axis tension test.

For the cruciform specimen in the biaxial tension test, the assumption of a linear relationship between stresses in the central tested zone and those in the loading arms was adopted. The former can be determined using the following relations:

$\sigma_{1}=\eta_{x} \frac{F_{x}}{A_{x}}, \sigma_{2}=\eta_{y} \frac{F_{y}}{A_{y}}$

where $F_{x}$ and $F_{y}$ are the longitudinal and transversal loads on the arms of cruciform specimen, $A_{x}$ and $A_{y}$ denote the longitudinal and transversal cross-sectional areas of the arms, respectively (the principal directions of the material are here in the $x$ and $y$ directions of the global coordinate system). $\eta_{x}$ and $\eta_{y}$ are the ratios of stresses in the central zone to those in the arms, which can be calculated with a finite-element (FE) model by applying the actual failure loads obtained in the experiment (mean values $\eta_{x}=2.32$, $\eta_{y}=2.32$ at $f=1 / 1$ and $\eta_{x}=2.52, \eta_{y}=1.77$ at $f=2 / 1$ were obtained from FE simulations).

The biaxial experimental data in the $\sigma_{1}-\sigma_{2}$ plane are compared with the discussed classical failure theories for the plain woven glass/epoxy composites, as shown in Fig. 7. It demonstrated that,

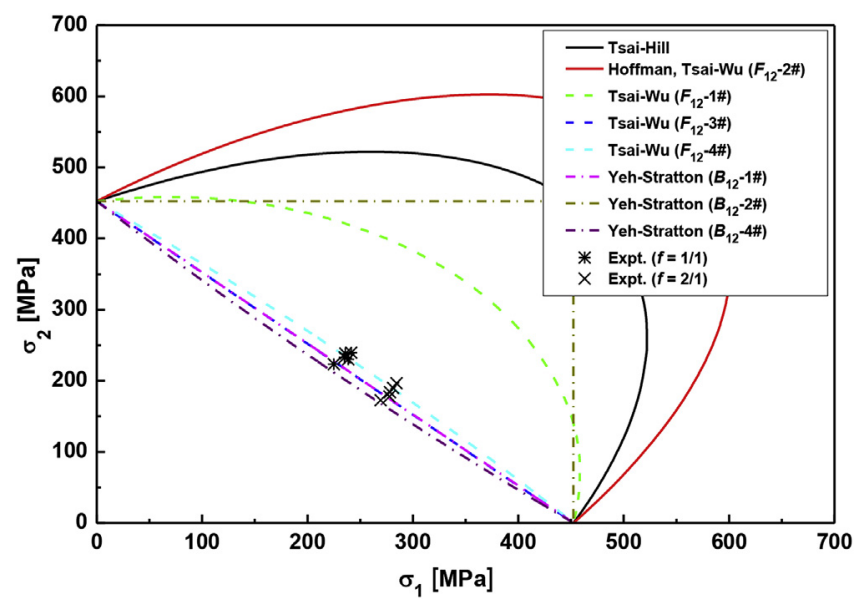

Fig. 7. Failure envelopes of biaxial tensile strength of plain woven glass/epoxy composite laminate.

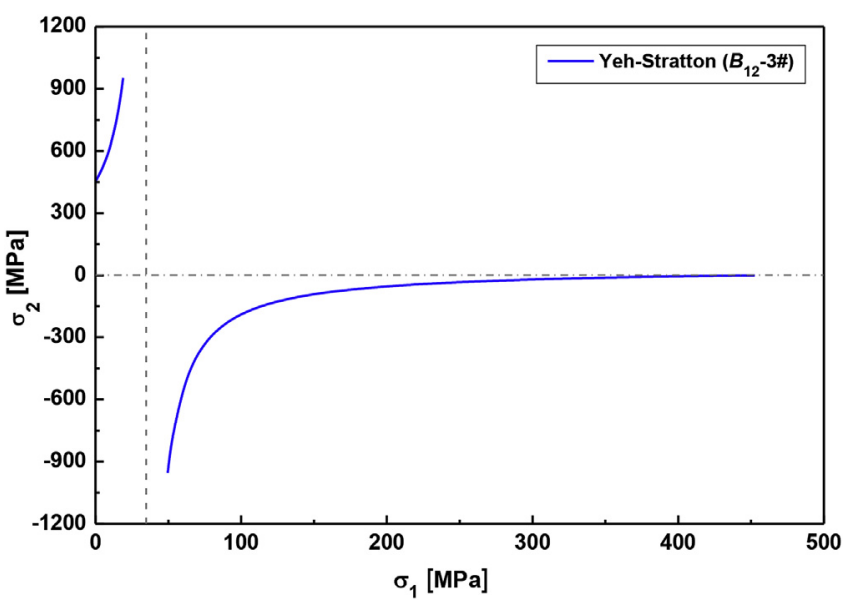

Fig. 8. Failure curves of Yeh-Stratton criterion with interaction coefficient for $B_{12}-3 \#$ in stress plane $\sigma_{1}-\sigma_{2}$

compared to the uniaxial strength $\left(X_{t}=452.4 \mathrm{MPa}\right)$, a lower biaxial tensile strength resulted, with the mean longitudinal ( $x$-axis) strength decreased by $48.0 \%$ and $38.5 \%$ at biaxial ratios $f=1 / 1$ and $2 / 1$, respectively. In their predictions of the biaxial strength of the plain woven glass/epoxy composites under in-plane biaxial loadings, the Tsai-Hill and Hoffman criteria overestimated the experimental observations with large deviations, while the Tsai-Wu criterion with $F_{12}-2 \#$ had the same results as the Hoffman criterion.

Considering the magnitude of $F_{12}$, the Tsai-Wu criterion resulted in another unreasonable prediction for $F_{12}=0$, while accurate results were obtained for the biaxial tensile strength under two biaxial load ratios for $F_{12}$-3\# (obtained from the $45^{\circ}$ off-axis tension test) and $F_{12}-4 \#$ (obtained from the biaxial tension test). In case of $F_{12}$-3\#, at the same failure stress for $\sigma_{1}$, the relative error between the predicted and mean experimental failure stress $\sigma_{2}$ was $-6.9 \%$ for $f=1 / 1$ and $-5.6 \%$ for $f=2 / 1$, while the respective differences were $1.1 \%$ and $4.1 \%$ for $F_{12}-4 \#$. According to the absolute differences between the predicted and experimental results, the Tsai-Wu with $F_{12}$-4\# demonstrated slight superiority compared to $F_{12}-3 \#$.

The Yeh-Stratton criterion showed different forms with different values of the interaction coefficient $B_{12}$. The criterion became a linear expression, with the difference between the predicted and experimental failure stress $\sigma_{2}$ of $-6.8 \%$ for $f=1 / 1$ and $-5.41 \%$ for $f=2 / 1$ in case of $B_{12}=0$, while it was reduced to the maximum stress criterion for $B_{12}-2 \#$. Its predictions were also acceptable for $B_{12}-4 \#$, resulting in differences between the predicted and experimental results of $-13.5 \%$ for $f=1 / 1$ and $-13.3 \%$ for $f=2 / 1$. However, two-branch discontinuous curves, as shown in Fig. 8, were observed for $B_{12}-3 \#$ (obtained from the $45^{\circ}$ off-axis tension test), demonstrating large deviations from the experimental data. The main reason for this might be that a significant effect of the failure shear stress in the $45^{\circ}$ off-axis tension test on the value of coefficient $B_{12}$, but no shear stress was considered in biaxial tension.

\subsection{Critical discussion}

The comparison observed between the experimental results and the theoretical predictions are here discussed critically in the light of the classical polynomial criteria used for failure analysis the plain woven glass/epoxy composites.

In Fig. 6, the predictions by all criteria show good agreement with the experimental data. Generally, the Tsai-Hill, Hoffman and Tsai-Wu criteria have a better (and similar) forecasting capability 
for the off-axis strength of the plain woven composites with the maximum relative error of $12.0 \%$ lower than the Yeh-Stratton criterion with its maximum relative error of $15.6 \%$ (see Table 4 ). For a small off-axis angle, $15^{\circ}$ in one case, the Tsai-Hill, Hoffman and Tsai$\mathrm{Wu}$ criteria show higher deviations for the experimental results, while they coincide better with the results for larger off-axis angles (i.e. $30^{\circ}$ and $45^{\circ}$ ). This phenomenon could be due to a crimp interchange in the weaving of the material as well as the accuracy of criteria. Furthermore, for the Tsai-Wu criterion, better estimations with high accuracy for the off-axis strength were observed when the interaction coefficient $F_{12}$ was obtained from the $45^{\circ}$ offaxis and biaxial tension tests. On the other hand, the Yeh-Stratton criterion with different interaction coefficients $B_{12}$ had similar prediction results, with slightly higher deviations for the off-axis strength apart of the case with $B_{12}-3 \#$. $B_{12}-3 \#$ was obtained from the $45^{\circ}$ off-axis tension test considering the effect of actual off-axis stresses, which led to high accuracy of the prediction.

In order to fully understand and generalize the predictive accuracy of the four criteria, the biaxial tension results obtained in experiments should also be analysed. There is an obvious imparity in the predictions of these criteria for the biaxial tensile strength of the material. The Tsai-Hill, Hoffman, Tsai-Wu (for $F_{12}-1 \#$ and $F_{12}-$ $2 \#$ ), and Yeh-Stratton (for $B_{12}-2 \#$ and $B_{12}-3 \#$ ) criteria were not able to predict accurately the biaxial strength of the plain woven composites, with the Yeh-Stratton criterion for $B_{12}-3 \#$ demonstrating no continuous and closed envelope in the $\sigma_{1}-\sigma_{2}$ plane. On the other hand, the Tsai-Wu (for $F_{12}-3 \#$ and $F_{12}-4 \#$ ) and Yeh-Stratton (for $B_{12}-1 \#=0$ and $B_{12}-4 \#$ ) criteria can be used to predict the biaxial strength of the material for different biaxial load ratios. Moreover, the Tsai-Wu criterion with the modified $F_{12}$ showed some superiority in comparison with the Yeh-Stratton criterion with the modified $B_{12}$. It should be noted that there is a limitation in the tension-tension quadrant for the studied results, and more test results in other stress quadrants are also needed for further development of the criteria.

Based on the above study, for the failure analysis of plain woven composites under multiaxial tension loads, the Tsai-Wu criterion with modified $F_{12}$ obtained from the $45^{\circ}$ off-axis or biaxial tension tests and the Yeh-Stratton criterion with $B_{12}=0$ or obtained from the biaxial tension test can be employed.

\section{Failure modes and mechanism}

\subsection{Macroscopic analysis}

The off-axis specimens demonstrated different macroscopic failure modes [36]: examples of broken samples are shown in Fig. 9. Note that the $0^{\circ}$ specimen (Fig. 9a) broke due to an interface fibrematrix or interlaminar delamination and fabric (or fibre) ruptures. In the off-axis specimens (Fig. 9b, $c$ and d), the fibres were cut offering only partial mechanical strength to the material. Furthermore, the fibres contributed to a decrease in strength of the material when the off-axis angle increased; this is supported by the test results reported in Fig. 6. A nearly flat fracture mode can be

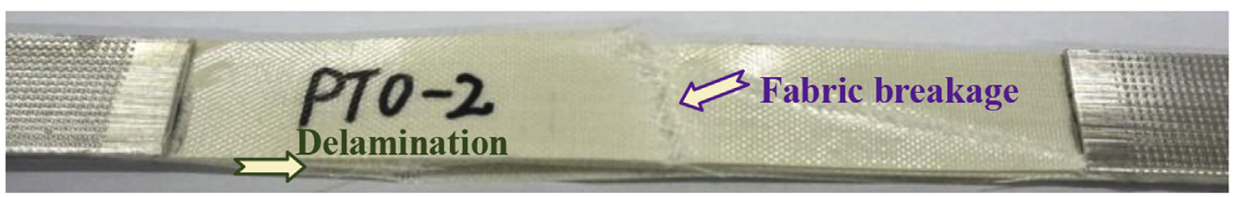

(a)

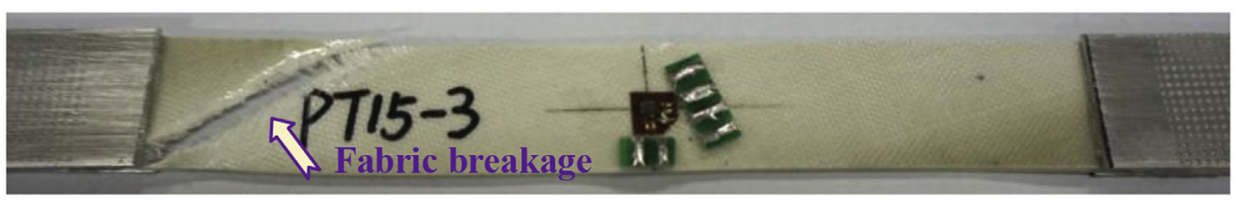

(b)

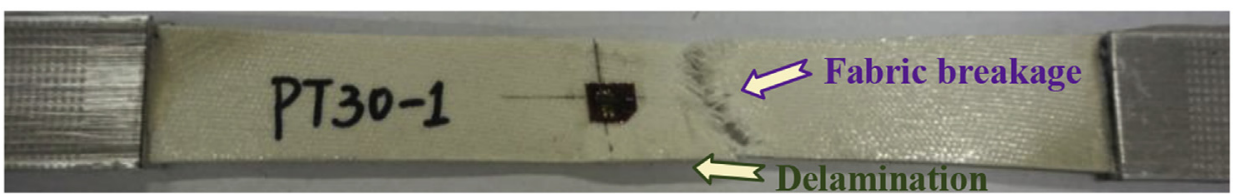

(c)

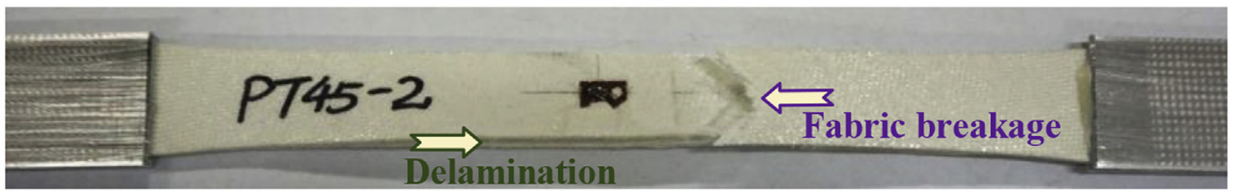

(d)

Fig. 9. Typical failures in specimens occurred during uniaxial tension tests for various angles: (a) $0^{\circ}$; (b) $15^{\circ}$; (c) $30^{\circ}$; (d) $45^{\circ}$. 


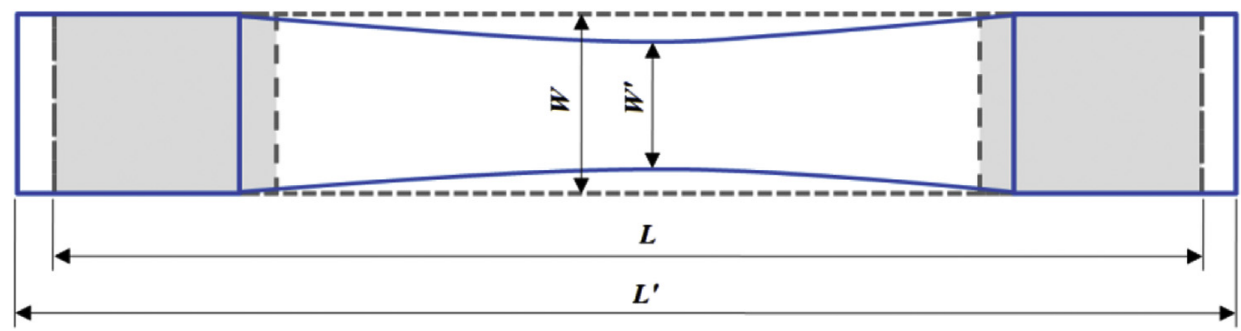

Fig. 10. Schematic of change in geometry of off-axis specimen during loading.

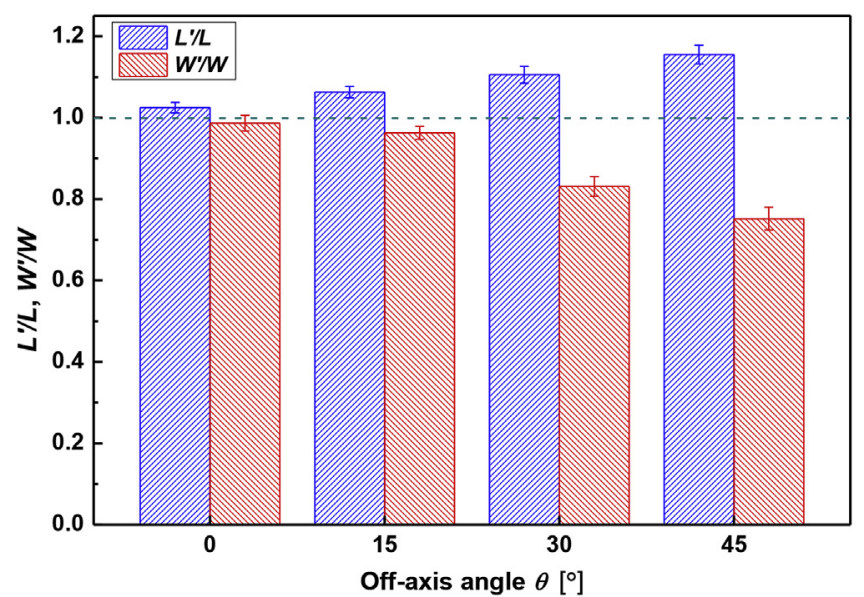

Fig. 11. Changes in geometry of off-axis specimens at failure.

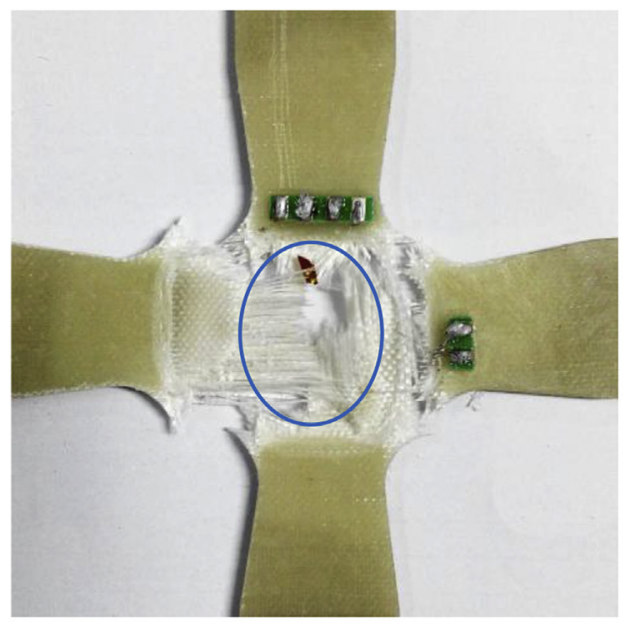

(a) due to the effect of interlaced fibre bundles, which deform simultaneously when the specimen is loaded. It is expected that scissoring (change in fibre orientation) is likely to take place. This may lead to the fracture surface to be oriented at an angle different from the original fibre orientation.

Off-axis specimens of the plain woven composites demonstrate a significant change in geometry during uniaxial tension loading, as shown in Fig. 10. Different levels of axial elongation and lateral contraction are observed, and the final changes in the relationship between the original and failure specimen are summarised in Fig. 11. With the increasing of off-axis angle, the ratio of $L$ ' (length of the failed specimen) and $L$ (length of the original specimen) increased almost linearly, while the ratio of $W$ (width of the failed specimen) and $W$ (width of the original specimen) declined sharply, achieving the minimum value at $45^{\circ}$ off-axis angle. This is a typical contraction phenomenon for the plain woven composites. Thus, the definitions of nominal stress and nominal strain are used in this paper.

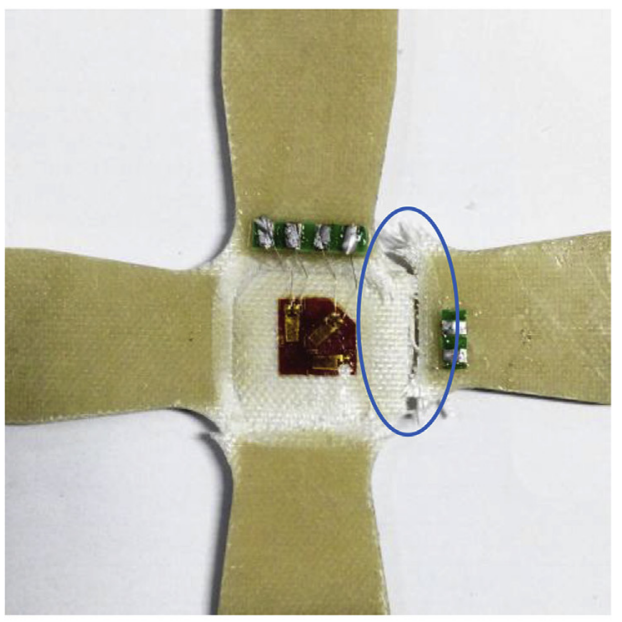

(b)

Fig. 12. Failure modes of plain woven glass/epoxy laminates under biaxial loadings: (a) $f=1 / 1$; (b) $f=2 / 1$.

seen in the on-axis specimen accompanied by delamination (Fig. 9a). The direction of fracture surface with fabric breakage shows $25^{\circ}-35^{\circ}$ with the loading direction in the $15^{\circ}$ off-axis specimens (Fig. 9b), while it is $40^{\circ}-60^{\circ}$ in the $30^{\circ}$ off-axis specimens with the failure modes of fabric breakage and delamination (Fig. 9c). Similar fracture modes can be observed for the $45^{\circ}$ off-axis specimens in Fig. 9d - fabric breakage and delamination; a V-shape fracture is also visible in the $45^{\circ}$ off-axis specimens. These failure modes in the off-axis specimens of the studied plain woven composites are distinct from those of unidirectional composites. This is
For the cruciform specimens of the plain woven glass/epoxy composites, the typical failure modes for different biaxial load ratios are presented in Fig. 12. A catastrophic failure due to fabric rupture primarily in the central testing zone of the cruciform specimen under biaxial tests with $f=1 / 1$ was recorded with a video camera. Fibre-bundle pull-outs and breakage were seen accompanied by delamination and matrix collapse (Fig. 12a). However, at ratio $f=2 / 1$, a root of the right loading arm in the $x$-direction failed catastrophically at the side of the central testing zone, as presented in Fig. 12b. Damage in the corners between the loading arms and 


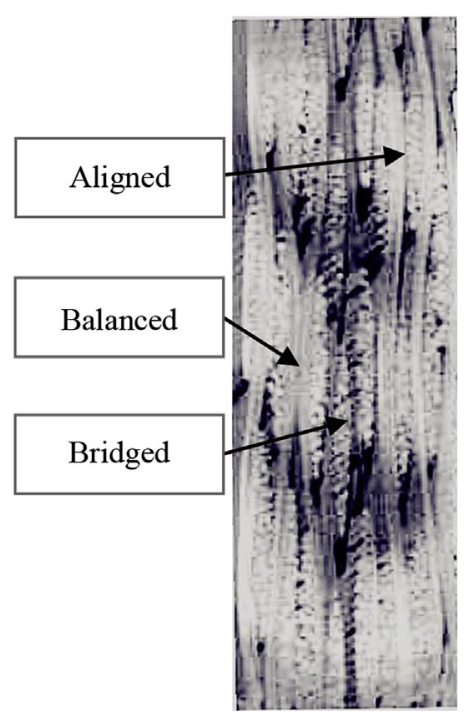

(a)

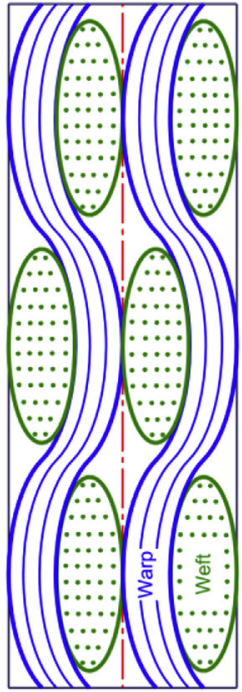

(b)

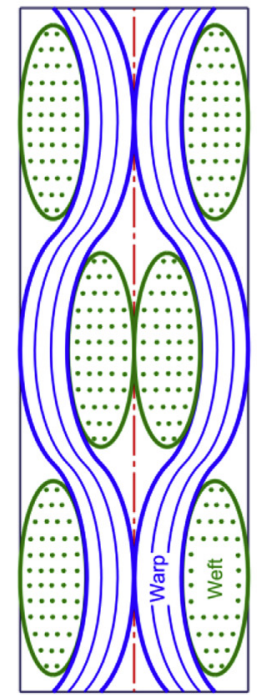

(c)

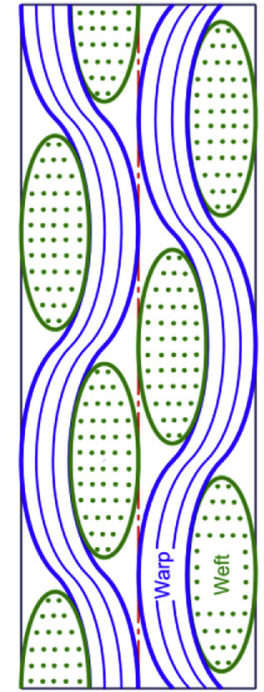

(d)

Fig. 13. Stacking configurations of layers in the plain woven glass/epoxy laminates: (a) microscopic image; (b) aligned; (c) balanced; (d) bridged.

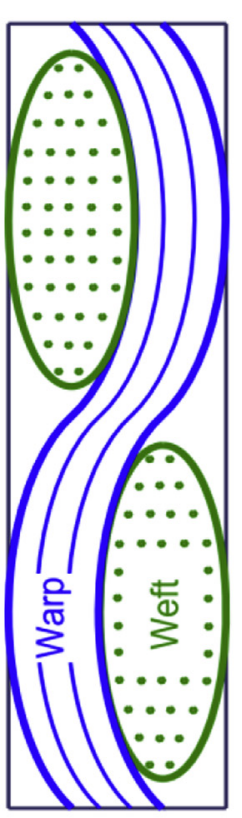

(a)

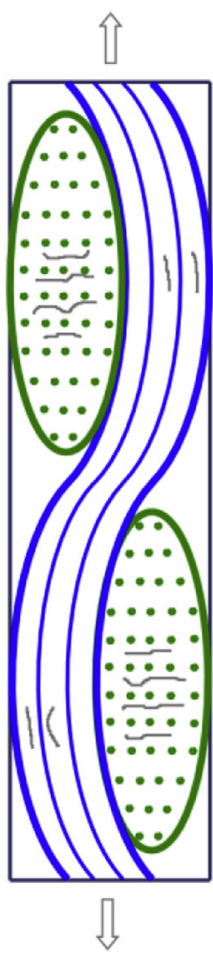

(b)

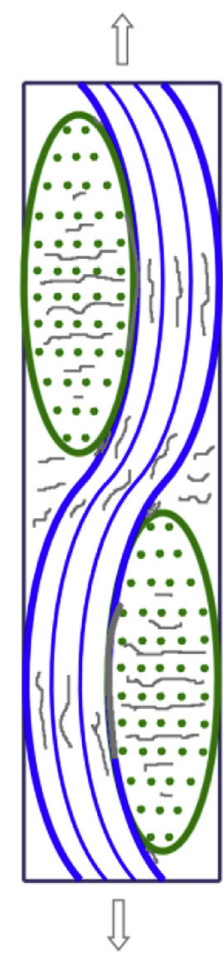

(c)

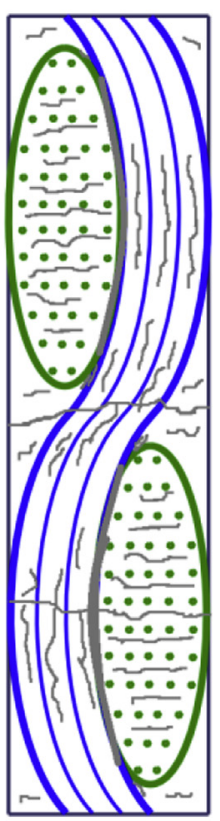

(d)

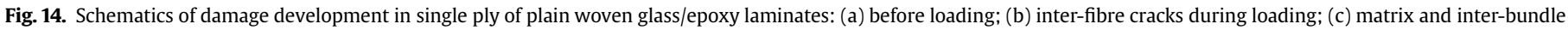
cracks during close-to-failure loading; (d) ultimate failure.

delamination in the central testing zone were also found.

\subsection{Microscopic damage analysis}

The studied plain woven glass/epoxy composite laminates were formed by stacking woven fabric layers one on top of the other without a possibility of considering the different orientations of the layers; as a result, different stacking patterns can be achieved caused by the misalignments between two adjacent layers. Fig. 13 shows three kinds of stacking configuration of layers in the plain woven glass/epoxy laminates. In a configuration without any relative shift between the adjacent layers (Fig. 13b), each layer is exactly 


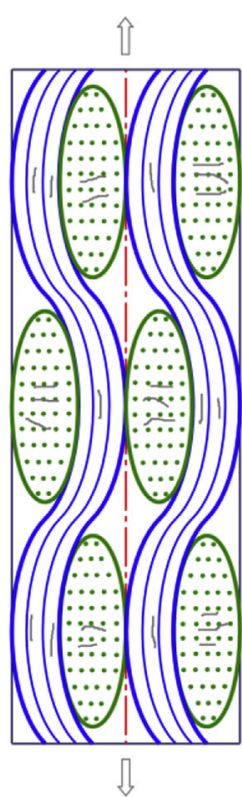

(a)

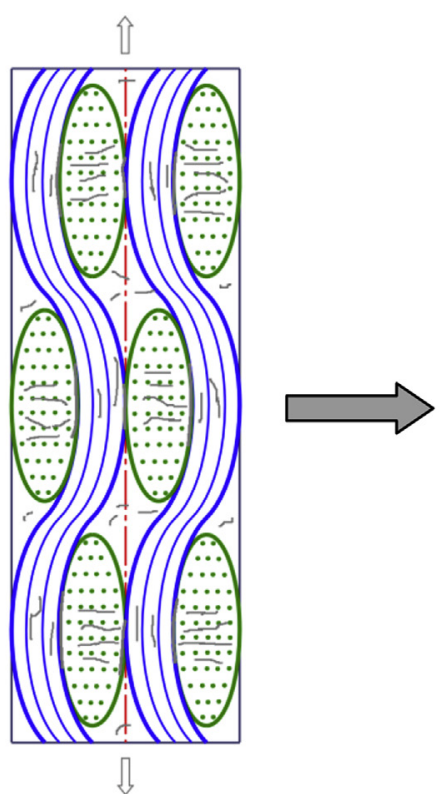

(b)

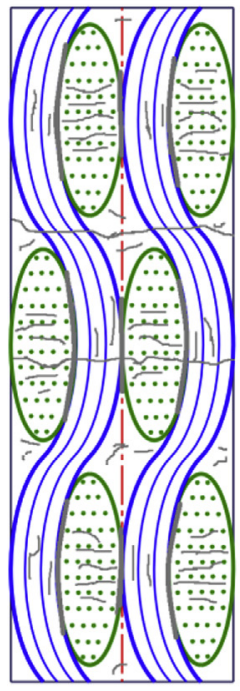

(c)

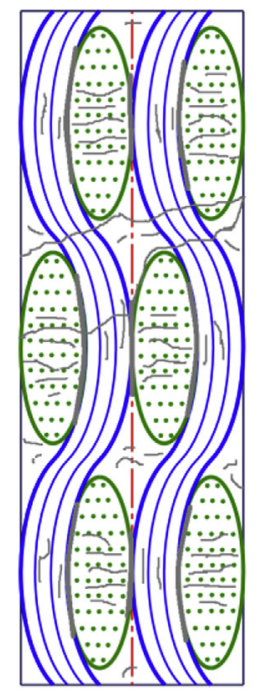

(d)

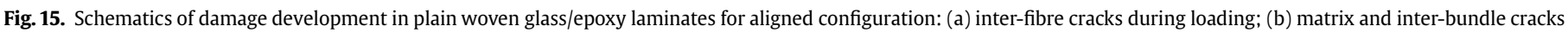
at close-to-failure loading; (c) ultimate failure under on-axis tension load; (d) ultimate failure under off-axis or biaxial loads.

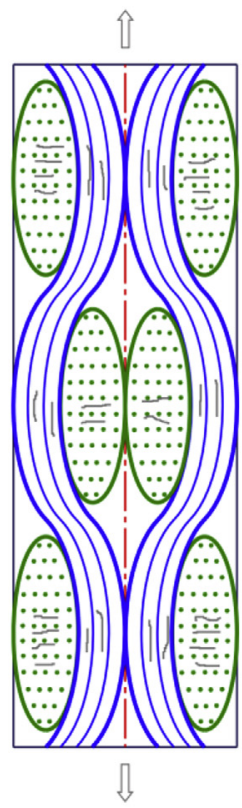

(a)

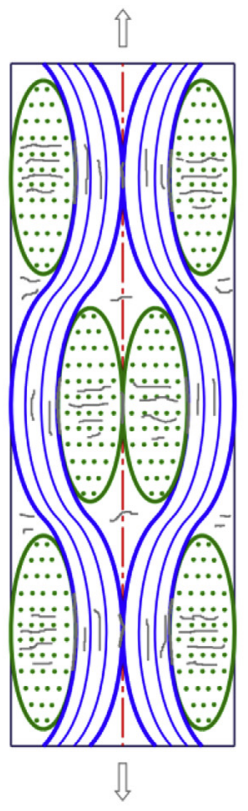

(b)

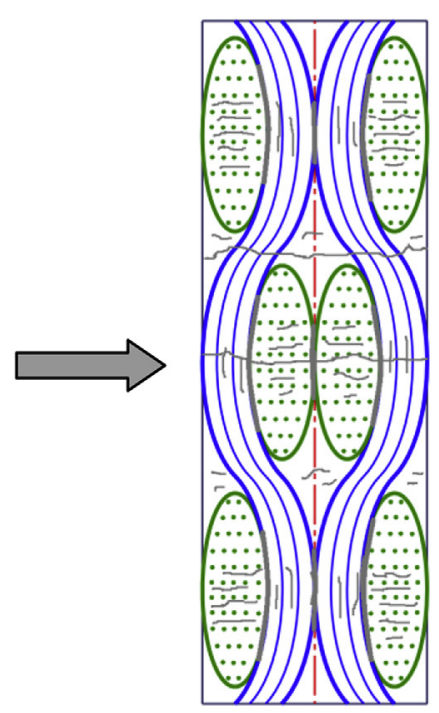

(c)

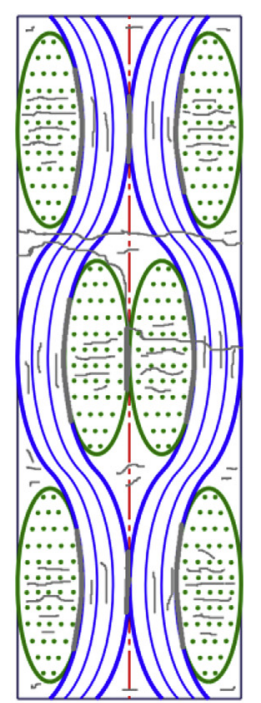

(d)

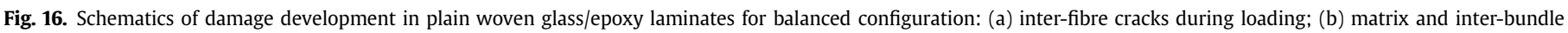
cracks at close-to-failure loading; (c) ultimate failure under on-axis tension load; (d) ultimate failure under off-axis or biaxial loads.

stacked over the adjacent layer; this configuration is referred to as aligned or stacked. In a balanced or symmetric configuration (Fig. 13c), each layer is exactly stacked face to face over the adjacent layer. In a configuration (Fig. 13d), the adjacent layers are shifted with respect to each other in both the warp (longitudinal) and weft (transverse) directions, i.e. the gap region of one layer is bridged by the interlacing region of the adjacent layer; this configuration is named bridged or nested. There is different microscopic failure mechanism in different stacking configurations of layers as well as under different loadings.

A schematic presentation of damage in a single ply of the plain woven glass/epoxy composite laminates under the static tensile loading are shown in Fig. 14, close-to-failure and ultimate failure loads. The initial failure, or cracks, will occur in the bundles of the 


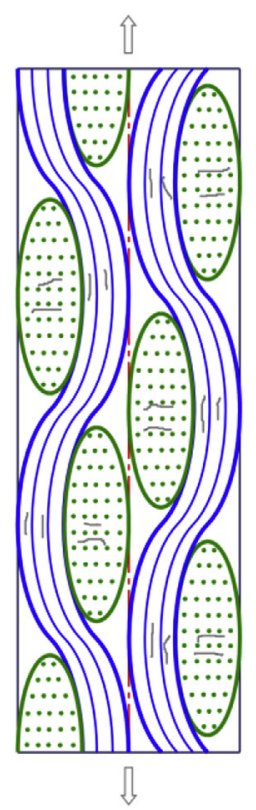

(a)

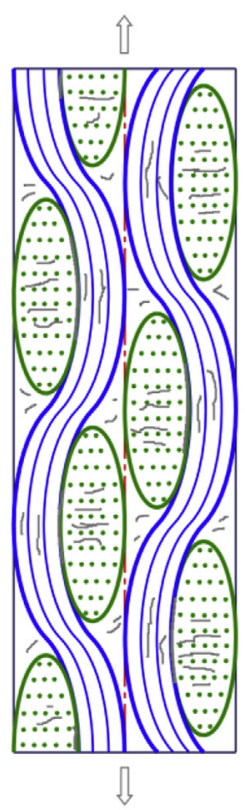

(b)

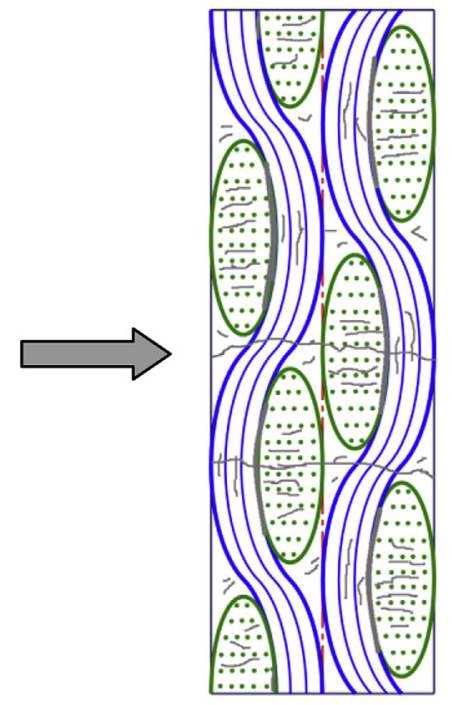

(c)

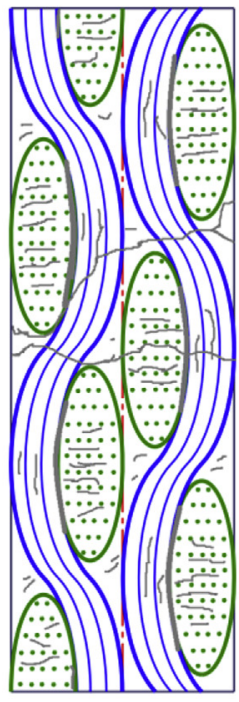

(d)

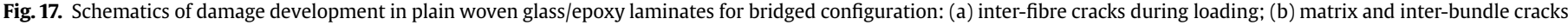
at close-to-failure loading; (c) ultimate failure under on-axis tension load; (d) ultimate failure under off-axis or biaxial loads.

interlacing region. As the loading increases, the failure progresses towards the mid-section of this region, accompanying bundle debonding and failure cracks in the matrix region between the interlacing regions. The instantaneous catastrophic fracture in the matrix and the interlacing regions occurs at the ultimate failure load (Fig. 14d). During loading, the geometry of the plain woven composite laminates also changes, as seen in the macroscopic failure modes in Figs. 9 and 10.

The microscopic damage modes in the plain woven composites are fibre/matrix interfacial debonding, matrix cracking, fibre or fabric breakage and crack coupling, which are similar to the damage mechanism observed in unidirectional laminates. For different stacking configurations, cracks in warp and weft bundles, transverse cracks in pure-matrix regions, delamination between warp and weft bundles, delamination between adjacent layers, and, finally, catastrophic fracture in the interlacing or matrix region can occur gradually (or simultaneously) with increasing load. The ultimate fracture can take place in the interlacing or matrix region based on the stacking configurations of the laminates and the types of load, as shown in Figs. 15-17.

For the aligned configuration, some nearly parallel cracks or fracture surfaces can be found in both the interlacing and matrix regions (Fig. 15c) under the on-axis tension load, while the misaligned cracks present damage localisation shifting from the interlacing region to the matrix region under off-axis or biaxial loads (Fig. 15d). Similar features can also be found in the balanced (Fig. 16) and bridged (Fig. 17) configurations.

It is known that mechanical properties of composites are closely related to their structure, and macroscopic failure modes depend even more on microscopic damage mechanism. SEM images of fracture surfaces of specimens subjected to uniaxial and biaxial tensions, as shown in Fig. 18, provide some useful insights into this. A series of clear oblique fracture sections of the fibres (highlighted with yellow encirclements; Fig. 18a, b and c) can be observed in failure off-axis specimens of the plain woven glass/epoxy composites, indicating a specific character of an off-axis failure mechanism. On the other hand, a group of comparatively smooth fracture surfaces are visible in the cruciform specimen at biaxial ratio $f=1 / 1$. Note that, apparently, the shapes of a fibre surface and matrix debris are compatible, and there are more matrix debris and broken fibres under off-axis loads due to the extrusion effect between interweaving fibre bundles. As presented in Fig. 19, a clear failure mode of debonding between the fibre bundles in the interlacing region and delamination between the adjacent layers are also prominent.

\section{Conclusions}

A number of experimental tests were carried out on off-axis and cruciform specimens of laminates to obtain the respective failure characteristics for plain woven glass/epoxy composites under offaxis and biaxial tension loads. The layer-by-layer stacking of the composite laminates was performed manually, assisted by the vacuum bagging technique. Four classical polynomial criteria (TsaiHill, Hoffman, Tsai-Wu and Yeh-Stratton) used for failure analysis of plain woven composites were compared and discussed, especially focusing on the effect of the interaction coefficients of normal stresses in the Tsai-Wu and Yeh-Stratton criteria. A comparison between the prediction results using these criteria and the data for multiaxial (i.e. off-axis and biaxial here) strength obtained with the tests was presented. For failure prediction in the plain woven composites under multiaxial tension loads, the Tsai-Wu criterion with the modified $F_{12}$ (obtained from the $45^{\circ}$ off-axis or biaxial tension tests) and the Yeh-Stratton criterion with $B_{12}=0$ (or obtained from the biaxial tension test) are the most suitable ones, where the Tsai-Wu criterion with the modified $F_{12}$ provides higher accuracy.

The failed specimens showed nearly distinct failure with specific fracture orientations, mainly exhibiting a fibre or fabric tensile fracture mode and a combination of matrix cracks and 


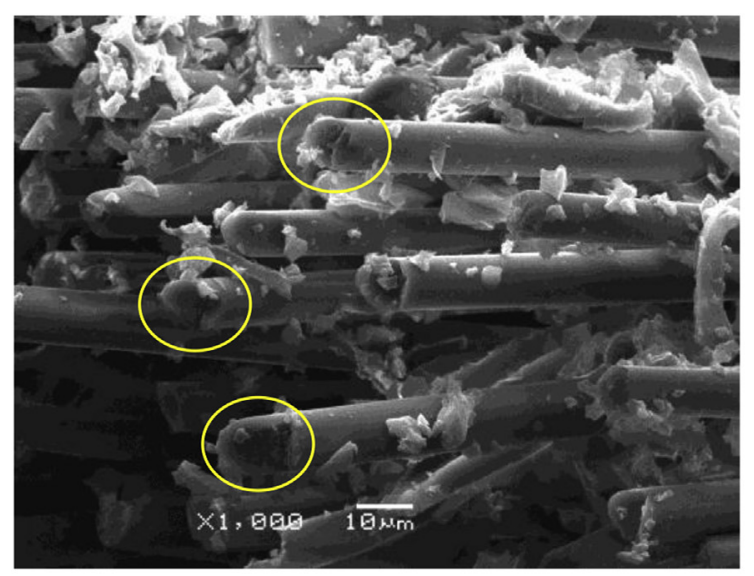

(a)

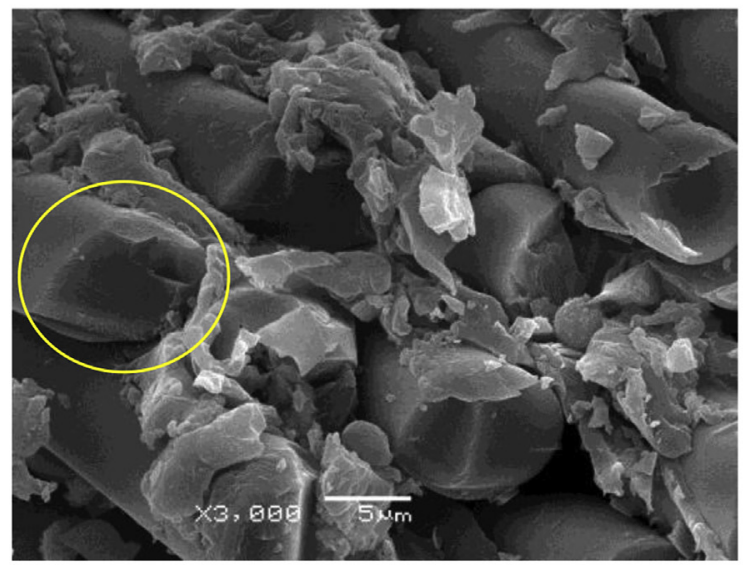

(c)

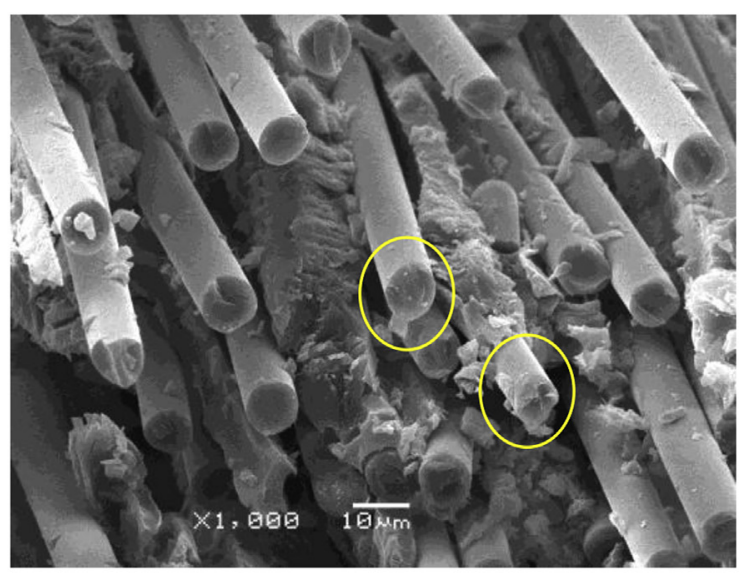

(b)

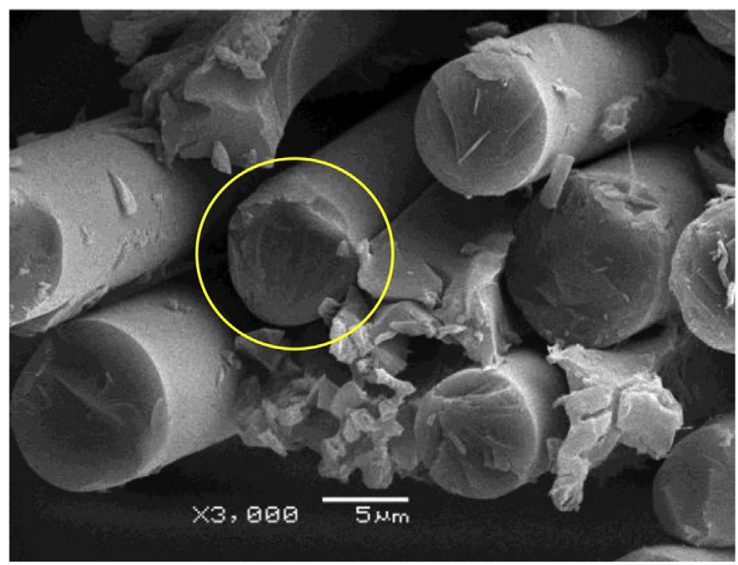

(d)

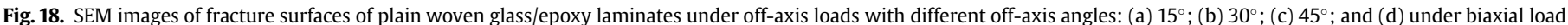
at biaxial ratio $f=1 / 1$.

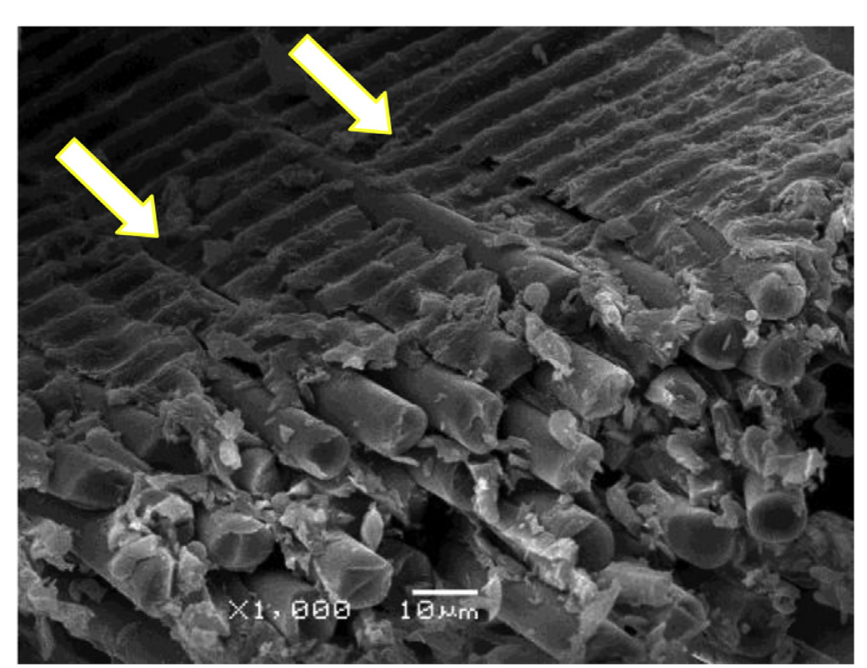

Fig. 19. Debonding of fibre bundles in interlacing region and delamination between adjacent layers. delamination in both the off-axis and cruciform samples. Furthermore, the expected pattern of macroscopic failure was observed in the cruciform specimen under $f=1 / 1$ biaxial loading, while it does not occur in the central testing zone but in the arm roots for $f=2 / 1$. Three main types of stacking configuration of layers in the plain woven glass/epoxy laminates were proposed for analysis of microscopic damage and macroscopic fracture. In SEM images, oblique fracture sections of the fibres with coexisting matrix debris can be observed in failure off-axis specimens, while comparatively smooth fracture surfaces were found in the cruciform specimen. A clear failure mode of debonding between the fibre bundles in the interlacing region and delamination between the adjacent layers are also prominent in the failed glass-fibre specimens.

\section{Acknowledgments}

This work was partially supported by the Fundamental Research Funds for the Central Universities, the Priority Academic Program Development of Jiangsu Higher Education Institutions (PAPD) and the Funding of Jiangsu Innovation Program for Graduate Education (Grant No. KYLX_0222). Furthermore, D. Cai would like to thank colleagues of the Composite Group at DTG-University of Padova (Dr. 
Marino Quaresimin and Dr. Paolo Andrea Carraro) for the fruitful discussion and suggestion when he visited DTG for an academic exchange.

\section{References}

[1] A.S. Kaddour, M.J. Hinton, P.D. Soden, A comparison of the predictive capabilities of current failure theories for composite laminates: additional contributions, Compos. Sci. Technol. 64 (3-4) (2004) 449-476.

[2] M.J. Hinton, A.S. Kaddour, P.D. Soden, A further assessment of the predictive capabilities of current failure theories for composite laminates: comparison with experimental evidence, Compos. Sci. Technol. 64 (3-4) (2004) 549-588.

[3] P.D. Soden, A.S. Kaddour, M.J. Hinton, Recommendations for designers and researchers resulting from the world-wide failure exercise, Compos. Sci. Technol. 64 (3-4) (2004) 589-604.

[4] R. Olsson, A survey of test methods for multiaxial and out-of-plane strength of composite laminates, Compos. Sci. Technol. 71 (6) (2011) 773-783.

[5] R. Talreja, Assessment of the fundamentals of failure theories for composite materials, Compos. Sci. Technol. 105 (2014) 190-201.

[6] T.A. Bogetti, J. Staniszewski, B.P. Burns, et al., Predicting the nonlinear response and progressive failure of composite laminates under triaxial loading: correlation with experimental results, J. Compos. Mater. 47 (6-7) (2013) 793-804.

[7] H.T. Hu, W.P. Lin, F.T. Tu, Failure analysis of fiber-reinforced composite laminates subjected to biaxial loads, Compos. Part B Eng. 83 (2015) 153-165.

[8] M.J. Hinton, A.S. Kaddour, P.D. Soden, Failure Criteria in Fibre Reinforced Polymer Composites: the World-wide Failure Exercise, Elsevier, 2004.

[9] M.J. Hinton, A.S. Kaddour, The background to the second world-wide failure exercise, J. Compos. Mater. 46 (19-20) (2012) 2283-2294.

[10] A.S. Kaddour, M.J. Hinton, P.A. Smith, et al., The background to the third world-wide failure exercise, J. Compos. Mater. 47 (20-21) (2013) 2417-2426.

[11] A.S. Chen, F.L. Matthews, A review of multiaxial/biaxial loading tests for composite materials, Composites 24 (5) (1993) 395-406.

[12] H. Thom, A review of the biaxial strength of fibre-reinforced plastics, Compos. Part A Appl. Sci. Manuf. 29 (8) (1998) 869-886.

[13] M. Quaresimin, 50th anniversary article: multiaxial fatigue testing of composites: from the pioneers to future directions, Strain 51 (1) (2015) 16-29.

[14] M. Quaresimin, L. Susmel, R. Talreja, Fatigue behaviour and life assessment of composite laminates under multiaxial loadings, Int. J. Fatigue 32 (1) (2010) $2-16$

[15] M. Quaresimin, P.A. Carraro, On the investigation of the biaxial fatigue behaviour of unidirectional composites, Compos. Part B Eng. 54 (2013) 200-208.

[16] M. Kawai, A phenomenological model for off-axis fatigue behavior of unidirectional polymer matrix composites under different stress ratios, Compos. Part A Appl. Sci. Manuf. 35 (7) (2004) 955-963.

[17] I.M. Daniel, JJ. Luo, P.M. Schubel, et al., Interfiber/interlaminar failure of composites under multi-axial states of stress, Compos. Sci. Technol. 69 (6) (2009) 764-771.

[18] A.E. Antoniou, D. Van Hemelrijck, T.P. Philippidis, Failure prediction for a glass/epoxy cruciform specimen under static biaxial loading, Compos. Sci. Technol. 70 (8) (2010) 1232-1241.

[19] H.W. Zhou, H.Y. Yi, L.L. Gui, et al., Compressive damage mechanism of GFRP composites under off-axis loading: experimental and numerical in vestigations, Compos. Part B Eng. 55 (2013) 119-127.

[20] Y. Ismail, D. Yang, J. Ye, A DEM model for visualising damage evolution and predicting failure envelope of composite laminae under biaxial loads, Compos. Part B Eng. 102 (2016) 9-28.

[21] P. Bere, P. Berce, O. Nemes, Phenomenological fracture model for biaxial fibre reinforced composites, Compos. Part B Eng. 43 (5) (2012) 2237-2243.

[22] Y. Zhou, Z. Lu, Z. Yang, Progressive damage analysis and strength prediction of 2D plain weave composites, Compos. Part B Eng. 47 (2013) 220-229.

[23] Y. Zhang, X. Song, Q. Zhang, et al., Fracture failure analysis and strength criterion for PTFE-coated woven fabrics, J. Compos. Mater. 49 (12) (2015) 1409-1421.

[24] A. Smits, D. Van Hemelrijck, T.P. Philippidis, et al., Design of a cruciform specimen for biaxial testing of fibre reinforced composite laminates, Compos. Sci. Technol. 66 (7) (2006) 964-975

[25] A. Makris, C. Ramault, D. Van Hemelrijck, et al., An investigation of the mechanical behavior of carbon epoxy cross ply cruciform specimens under biaxial loading, Polym. Compos. 31 (9) (2010) 1554-1561.

[26] E. Lamkanfi, W. Van Paepegem, J. Degrieck, et al., Strain distribution in cruciform specimens subjected to biaxial loading conditions. Part 1: twodimensional versus three-dimensional finite element model, Polym. Test. 29 (1) (2010) 7-13.

[27] E. Lamkanfi, W. Van Paepegem, J. Degrieck, et al., Strain distribution in cruciform specimens subjected to biaxial loading conditions. Part 2: influence of geometrical discontinuities, Polym. Test. 29 (1) (2010) 132-138.

[28] M.C.S. Moreno, J.J.L. Cela, Failure envelope under biaxial tensile loading for chopped glass-reinforced polyester composites, Compos. Sci. Technol. 72 (1) (2011) 91-96.

[29] M.C.S. Moreno, J.L.M. Vicente, J.J.L. Cela, Failure strain and stress fields of a chopped glass-reinforced polyester under biaxial loading, Compos. Struct. 103 (2013) 27-33.

[30] A.S. Torres, A.K. Maji, The development of a modified bi-axial composite test specimen, J. Compos. Mater. 47 (19) (2013) 2385-2398.

[31] D. Cai, G. Zhou, V.V. Silberschmidt, Effect of through-thickness compression on in-plane tensile strength of glass/epoxy composites: experimental study, Polym. Test. 49 (2016) 1-7.

[32] V.D. Azzi, S.W. Tsai, Anisotropic strength of composites, Exp. Mech. 5 (9) (1965) 283-288.

[33] O. Hoffman, The brittle strength of orthotropic materials, J. Compos. Mater. 1 (2) (1967) 200-206.

[34] S.W. Tsai, E.M. Wu, A general theory of strength for anisotropic materials, J. Compos. Mater. 5 (1) (1971) 58-80.

[35] H.Y. Yeh, C.H. Kim, The Yeh-Stratton criterion for composite materials, J. Compos. Mater. 28 (10) (1994) 926-939.

[36] D. Cai, G. Zhou, X. Wang et al., Experimental investigation on mechanica properties of unidirectional and woven fabric glass/epoxy composites under off-axis tensile loading, Polym. Test. 58 (2017) 142-152. 